\title{
Osteoarthrosis: Analyze of the Molar Bite Force, Thickness and Masticatory Efficiency
}

\author{
Mariah Acioli Righetti', Oswaldo Luiz Stamato Taube ${ }^{2}$, \\ Marcelo Palinkas ${ }^{1,3,4}$, Lígia Maria Napolitano Gonçalves', \\ Danilo Stefani Esposto', Edneia Corrêa de Mello', Isabela Hallak \\ Regalo', Simone Cecilio Hallak Regalo ${ }^{1,4}$, Selma Siéssere ${ }^{1,4}$
}

${ }^{1}$ School of Dentistry of Ribeirão Preto, University of São Paulo, São Paulo, Brazil; ${ }^{2}$ UNIFAFIBE University Center, Bebedouro, São Paulo, Brazil;

${ }^{3}$ Anhanguera Faculty, Ribeirão Preto, São Paulo, Brazil;

${ }^{4}$ National Institute and Technology - Translational Medicine (INCT.TM),

São Paulo, Brazil

Received January 29, 2020; Accepted May 28, 2020.

Key words: Osteoarthrosis - Bite force - Thickness - Myoelectric activity Masticatory muscles

\begin{abstract}
Osteoarthrosis is a disorder of synovial joints, resulting from destruction of the cartilage and subchondral bone. The present study is aimed to investigate the molar bite force, thickness and efficiency of the masseter and temporalis muscles of subjects with osteoarthrosis. A total of forty-eight subjects participated in the study. They were distributed into two groups: with osteoarthrosis $(n=24)$ and asymptomatic controls $(n=24)$. Subjects were analyzed on the basis of maximal molar bite force (right and left side), thickness (mandibular rest and dental clenching in maximal voluntary contraction) and electromyographic activity of masticatory cycles through the linear envelope integral in habitual (raisins and peanuts) and non-habitual (Parafilm M) chewing of the masseter and temporalis muscles. All the data were analyzed statistically using $t$-test with a significance level of $p \leq 0.05$. There was no difference between groups in maximal molar bite force, muscle thickness and non-habitual chewing. Differences were found on the raisins $(p=0.02)$ and peanuts $(p=0.05)$ chewing for right temporal muscle, with reduced masticatory
\end{abstract}

This study was supported by National Institute and Technology - Translational Medicine (INCT.TM).

Mailing Address: Prof. Marcelo Palinkas, PhD., School of Dentistry of Ribeirão Preto, University of São Paulo, Avenida do Café s/n, Bairro Monte Alegre CEP 14040-904, Ribeirão Preto, São Paulo, Brazil; e-mail: palinkas@usp.br 
muscle efficiency in osteoarthrosis subjects. This study showed that osteoarthrosis induces negative changes in habitual chewing, highlighting the efficiency of the right temporalis muscles. The greater temporal muscle activity in subjects with osteoarthrosis may compromise chewing and consequently the nutritional status of adult subjects.

\section{Introduction}

Osteoarthrosis is a degenerative joint disease with slow progression characterized by attacks the synovial joints, involved in the stomatognathic system, particularly in the temporomandibular joints, by the sequel of displacement and perforation of the disc (Levorová et al., 2016). It is characterized by the destruction or alteration of articular cartilage with resultant bone repercussions (Mau-Moeller et al., 2017).

Clinically it can be defined by an insufficiency of the articular cartilage, resulting from mechanical, genetic, hormonal, bone or metabolic factors. These causes lead to an imbalance between the synthesis and degradation of articular cartilage and the subchondral bone (Camanho et al., 2011). This disease causes functional changes in $15 \%$ of the worldwide adult population, affecting subjects mainly subjects over 60 years old (Santos et al., 2014).

The temporomandibular joint is a part of the stomatognathic system, together with the bones, muscles, teeth, lips, tongue, cheeks, glands, arteries, veins and nerves. The structures of this system act together in such a way that any specific anatomical or functional modification can lead to an imbalance (Mupparapu et al., 2019).

Alterations in the components of the stomatognathic system, and specifically in the case of the temporomandibular joint, can lead to the development of temporomandibular disorders (Smaglyuk and Liakhovska, 2019). As such, this system has been the focus of several studies, mainly in groups of subjects with systemic pathological alterations similar to osteoarthrosis (Palinkas et al., 2018).

The null hypothesis of this study was that osteoarthrosis in its initial phase would not influence molar bite force, muscle thickness and efficiency of masticatory muscles, thus not interfering with the functioning of the stomatognathic system. The objective of this study was to verify whether osteoarthrosis causes functional alterations in the stomatognathic system of subjects with an initial diagnosis of the disease, when compared with subjects without osteoarthrosis.

\section{Material and Methods}

Study population

This study was approved by the Research Ethics (protocol \#.55505316.8.0000.5419). All the subjects signed the free and informed consent. The subjects were diagnosed by a rheumatologist, following the guidelines of the American College of Rheumatology and recruited from specialized referral 
centers for the treatment of chronic degenerative diseases in the cities of Batatais, Bebedouro and Ribeirão Preto, São Paulo, Brazil.

The post hoc sample size was calculated based on an error of $10 \%(\alpha=0.10)$, and a power test of $85 \%$ for the main result of the electromyographic activity in the condition of raisin chewing (average values of the right temporal muscle). The value for the group with osteoarthrosis was $1.27(0.86)$ and for the control group it was $0.81(0.43)$ and the effect size was 0.67 . The minimum sample size was 48 subjects (24 for each group). The sample size was calculated using the free-access software program G* Power version 3.1.9.2 (Franz Faul, Kiel University, Kiel, Germany).

A total of 72 subjects of both genders, aged between 40 and 70 years, were selected. In accordance with the inclusion and exclusion criteria, a final 12 subjects were selected for the group with osteoarthrosis ( $n=24$; mean \pm SD: $53.6 \pm 1.6$ years and $28.61 \pm 0.98 \mathrm{~kg} / \mathrm{m}^{2}$ ), Angle Class I, contact pattern in maximum intercuspal position with tooth to two tooth occlusion and presence of all permanent teeth (except third molars) were selected. The disease-free group ( $n=24$; average \pm SD: $52.3 \pm 1.7$ years and $28.16 \pm 0.78 \mathrm{~kg} / \mathrm{m}^{2}$ ) was composed of dentate individuals, without temporomandibular dysfunction (RDC/TMD) who were age-, gender-, weight-, and height-matched with subjects in the osteoarthrosis group.

The exclusion criteria involved absence of dental element (upper and lower); the temporomandibular dysfunction; presence of dental restorations with risk of fractures; and use of anti-inflammatories, analgesics and muscle relaxants that could interfere in neuromuscular physiology (da Silva et al., 2019).

\section{Maximal bite force analysis}

Digital dynamometer, model IDDK (Kratos, Cotia, São Paulo, Brazil), with a $1000 \mathrm{~N}$ capacity, adapted to the mouth was used for the molar bite force records. Three records were obtained of the molar bite force of the right and left molar region (Palinkas et al., 2010; Verri et al., 2019), alternating between the sides. There was a two-minute rest period between each measurement. The highest value out of three records was considered as the subject's maximal bite force (Castelo et al., 2010).

\section{Ultrasound analysis}

The portable ultrasound device (NanoMaxx; SonoSite Inc, Bothell, WA, USA) with $10 \mathrm{MHz}$ linear-array transducer placed transversally was used to measure the thickness (centimeters) of the masseter and temporalis muscles fibers at rest and dental clenching in maximal voluntary contraction (Bertram et al., 2003), considering the bottom of the masseter muscle at $2.75 \mathrm{~cm}$ above the jaw angle toward the upper eyelid and the anterior temporalis muscle, and at $1.25 \mathrm{~cm}$ posterior and superior to the outside corner of the eye (da Silva et al., 2017). The location was confirmed by muscle palpation and movement of the linear transducer. For each clinical condition, three exams were conducted with an interval of 2 min between each acquisition. 


\section{Electromyographic analysis - efficiency}

The electromyographic signals of the masticatory cycles (masseter and temporalis muscles) were collected using Trigno electromyography equipment (Delsys Inc., Boston, MA, USA), wireless surface electrodes, and followed the SENIAN (Surface Electromyography for the Non-Invasive Assessment of Muscles) guideline (Hermens et al., 2000).

Electromyographic recordings were performed of the masticatory cycles through the ensemble average analysis, which consists of using the integrated amplitude values of the linear envelopment of the masticatory cycles (Siéssere et al., 2009). The electromyographic signals were acquired in the habitual (raisins and peanuts) and non-habitual (Parafilm M) chewing. Parafilm M (Pechinery Plastic Packaging, Batavia, IL, USA) is constituted by a sheet of paraffin, which was folded $(18 \times 17 \times 4 \mathrm{~mm}$, weight $245 \mathrm{mg})$ placed on both sides of the dental arches.

During the non-habitual chewing, subjects were asked to make a movement of short opening to reduce the effects of the change in length $x$ tension in the muscle, in typical dynamic records. The data of all the masticatory cycles were collected in $10 \mathrm{~s}$.

Three initial masticatory cycles were excluded since, at the beginning of the masticatory process, the first cycles vary considerably during mandibular movements. Therefore, to calculate the results obtained in this study from the integral of the linear envelope of the masticatory cycles, the initial masticatory cycles were eliminated while the central cycles of the electromyographic were maintained (Siéssere et al., 2009; da Silva et al., 2017).

\section{Statistical analysis}

In the analysis of the results, the data showed normal distribution (Shapiro-Wilk normality test: $p \leq 0.05$ ). Data on maximal bite force, thickness and normalized electromyographic data were submitted to statistical analysis using IBM SPSS Statistics for Windows, version 22.0 (IBM SPSS, IBM Corp., Armonk, NY, USA). Results were obtained by descriptive analysis (mean and standard error) for each variable. Values were compared by using the Student's $t$-test, with statistical significance set at $\mathrm{p}$-values $<0.05$.

\section{Results}

No differences were found between groups in the maximal molar bite force (Table 1) and muscle thickness (Table 2) values. The standard electromyographic data for habitual (peanuts and raisins) and non-habitual (Parafilm M) chewing for the groups are shown in Table 3. Differences were found on the raisins $(p=0.02)$ and peanuts $(p=0.05)$ chewing for right temporal muscle, with reduced masticatory muscle efficiency in osteoarthrosis subjects. 


\section{Discussion}

This study investigated the molar bite force, thickness and efficiency of the masseter and temporalis muscles of subjects with osteoarthrosis. In the present study, it was observed that there was no difference in comparisons between groups in the molar bite force (right and left), but it is documented that the higher the bite force, the better the performance of the masticatory muscles, and consequently an increased functional capacity of the stomatognathic system (Palinkas et al., 2016; Goiato et al., 2017). Although bite force results showed no difference in our study, it was evident that the function of the stomatognathic system of subjects with osteoarthrosis was compromised based on the results obtained in the masticatory efficiency analysis.

In this study, the position of the transducer was determined by the palpation of the muscles at rest and during maximal voluntary contraction (Levorová et al., 2016). This allowed us to obtain high quality images, and allowed us to identify the mandible branch, as well as the temporal bone. This ensured the correct collection and

Table 1 - Mean values (standard error) and statistical significance $(p \leq 0.05)$ of the right and left molar bite force (Newton) for osteoarthrosis (OAG) and without the disease (CG) groups

\begin{tabular}{lccc}
\hline Bite force & OAG & CG & P-value \\
\hline Right molar & $251 \pm 21$ & $281 \pm 31$ & 0.52 \\
Left molar & $260 \pm 21$ & $270 \pm 30$ & 0.83 \\
\hline
\end{tabular}

Table 2 - Mean values (standard error) and statistical significance $(p \leq 0.05)$ of the thickness $(\mathrm{cm})$ of the right masseter (RM), left masseter (LM), right temporal (RT) and left temporal (LT) muscles at rest and maximal voluntary contraction (MCV) in osteoarthrosis disease (OAG) and without the disease (CG) groups

\begin{tabular}{lccc}
\hline $\begin{array}{l}\text { Mandibular tasks } \\
\text { and muscles }\end{array}$ & OAG & CG & P-value \\
\hline \multicolumn{2}{c}{ Rest } \\
\hline RM & $0.90 \pm 0.06$ & $0.81 \pm 0.03$ & 0.21 \\
LM & $0.90 \pm 0.03$ & $0.88 \pm 0.03$ & 0.70 \\
RT & $0.38 \pm 0.02$ & $0.39 \pm 0.03$ & 0.75 \\
LT & $0.36 \pm 0.02$ & $0.40 \pm 0.02$ & 0.21 \\
\hline \multicolumn{5}{c}{$M V C$} & & \\
\hline RM & $1.27 \pm 0.06$ & $1.23 \pm 0.04$ & 0.65 \\
LM & $1.28 \pm 0.06$ & $1.27 \pm 0.04$ & 0.86 \\
RT & $0.48 \pm 0.02$ & $0.45 \pm 0.02$ & 0.38 \\
LT & $0.46 \pm 0.02$ & $0.56 \pm 0.08$ & 0.25 \\
\hline
\end{tabular}


Table 3 - Mean values (standard error) of the normalized electromyographic data and statistical significance $(p \leq 0.05) *$ of habitual and non-habitual chewing in osteoarthrosis disease (OAG) and without the disease (CG) groups for right masseter (RM), left masseter (LM), right temporal (RT) and left temporal (LT) muscles

\begin{tabular}{lcccc}
\hline \multirow{2}{*}{ Chewing } & Muscles & \multicolumn{2}{c}{ Groups } & \multirow{2}{*}{ P-value } \\
\cline { 3 - 4 } & & OAG & CG & \\
\hline \multirow{3}{*}{ Peanuts } & RM & $0.85 \pm 0.10$ & $0.95 \pm 0.09$ & 0.35 \\
& LM & $0.86 \pm 0.08$ & $0.85 \pm 0.09$ & 0.91 \\
& RT & $1.08 \pm 0.10$ & $0.82 \pm 0.81$ & $0.05^{*}$ \\
& LT & $0.87 \pm 0.09$ & $0.86 \pm 0.09$ & 0.98 \\
\hline \multirow{3}{*}{ Raisins } & RM & $0.89 \pm 0.11$ & $0.74 \pm 0.10$ & 0.34 \\
& LM & $0.68 \pm 0.09$ & $0.80 \pm 0.09$ & 0.37 \\
& RT & $1.27 \pm 0.17$ & $0.82 \pm 0.08$ & $0.02^{*}$ \\
Parafilm M & LT & $0.91 \pm 0.12$ & $0.84 \pm 0.08$ & 0.61 \\
\hline & RM & $0.80 \pm 0.10$ & $0.98 \pm 0.09$ & 0.21 \\
& LM & $0.85 \pm 0.09$ & $0.84 \pm 0.09$ & 0.80 \\
& RT & $0.90 \pm 0.08$ & $0.86 \pm 0.08$ & 0.80 \\
& LT & $0.80 \pm 0.08$ & $0.91 \pm 0.06$ & 0.30 \\
\hline
\end{tabular}

measurement of the images of the masseter and temporalis muscles (Kubota et al., 1998). The thickness of the masseter and temporalis muscles of the subjects with osteoarthrosis in this study were not different when compared to the control group.

Our results are like the findings of Rodrigues et al. (2017) who analyzed subjects with rheumatoid arthritis. They also did not observe differences in the thickness of the masseter and temporal muscles in comparison with control subjects. Thus, these previous results agree with our current findings that subjects with osteoarthrosis show no presence of muscle hypertrophy or atrophy.

In the habitual chewing of raisins was observed functional alteration in masticatory efficiency, especially for the right temporal muscle. A greater recruitment of the fibers of the right temporal muscle was required in the subjects affected by osteoarthrosis, when compared to the group without the disease. The same result was also observed when we analyzed the habitual chewing of peanuts, with a significantly higher recruitment of the right temporalis muscle in the subjects affected by osteoarthrosis. Such a condition can lead to a decrease in masticatory efficiency and considerably more physical effort (Kumai, 1993; Gonçalves et al., 2018; da Silva et al., 2019).

Another hypothesis to explain our results in habitual chewing would be pathological changes in the temporomandibular joint of individuals with osteoarthritis such as synovial membrane hyperplasia, chronic inflammatory infiltrate, disorganization of the collagen fibers, greater thickness of the articular 
disc, reduced of proteoglycans content, a decreased thickness of articular cartilage, lower feed intake, higher activity of metalloproteinases, and higher concentrations of interleukins and tumour necrosis factor $\alpha$, which could promote negative functional changes in the stomatognathic system (Lemos et al., 2018). In this study it was not evaluated if the temporomandibular joint was affected with osteoarthritis.

In this study it was not evaluated if their subjects suffered from bilateral or unilateral osteoarthrosis and which side was affected, because there was no confirmation by looking at retrospective CT of the selected subjects (Lehman et al., 2009; Haj-Mirzaian et al., 2019). The use of retrospective computed tomography is recommended for the diagnosis of degenerative diseases of the temporomandibular joint to reduce false negatives which may be found by panoramic radiographs and magnetic resonance imaging (Kaimal et al., 2018).

This would probably be a factor that could explain the only significant result related to the finding of electromyographic activity in the right temporal muscle. This may suggest that the temporomandibular joint side possibly affected by osteoarthrosis reflects in the recruitment of motor units of the temporal muscle.

This same muscle also presented higher activity in the non-habitual chewing of Parafilm M, but without difference. The absence of difference may be related to reduced and controlled movement of the jaw in this clinical condition, decreasing the effects of changing length and muscle tension (De Luca, 1997).

In our study, masticatory activity was lower (electromyographic activity) when chewing of foods of soft consistency when compared with chewing foods of hard consistency. These results agree with those of Komino and Shiga (2017) who verified that the value of the masseter muscle envelope integral increased significantly as the amount of gelatine increased in the food (gum). That is, the harder the food, the higher the activity required by the muscle.

The limitations of this study are as follows. First, we did not use retrospective computed tomography to determine if there was involvement of the temporomandibular joint and other structural components of this joint in subjects with the initial stages of osteoarthrosis. Secondly, our sample selection of subjects with osteoarthrosis in the initial phase may be a limitation, given that it could influence the absence of severe alterations in reflexes, muscle strength or muscle thickness. As such, future studies should be designed specifically to address these problems.

Given the results of this study, we reject our null hypothesis as, even in the initial phase; osteoarthrosis had a negative impact on the subjects' lives and caused significant alterations in the electrical activity of the musculature analyzed during masticatory efficiency.

\section{Conclusion}

The results suggest that osteoarthrosis induces negative changes in habitual chewing highlighting the efficiency of the right temporalis muscles. 


\section{References}

Bertram, S., Brandlmaier, I., Rudisch, A., Bodner, G., Emshoff, R. (2003) Cross-sectional characteristics of the masseter muscle: an ultrasonographic study. Int. J. Oral Maxillofac. Surg. 32, 64-68.

Camanho, G. L., Imamura, M., Lars Arendt-Nielsen, L. (2011) Genesis of pain in arthrosis. Rev. Bras. Ortop.

46, 14-17

Castelo, P. M., Pereira, L. J., Bonjardim, L. R., Gavião, M. B. (2010) Changes in bite force, masticatory muscle thickness, and facial morphology between primary and mixed dentition in preschool children with normal occlusion. Ann. Anat. 192, 23-26.

da Silva, J. M., Pires, C. P. A. B., Rodrigues, L. A. M., Palinkas, M., De Luca Canto, G., de Vasconcelos, P. B., Rancan, S. V., Semprini, M., Siéssere, S., Regalo, S. C. (2017) Influence of mandibular tori on stomatognathic system function. Cranio 35, 30-37.

da Silva, N., Verri, E., Palinkas, M., Hallak, J., Regalo, S., Siéssere, S. (2019) Impact of Parkinson's disease on the efficiency of masticatory cycles: Electromyographic analysis. Med. Oral Patol. Oral Cir. Bucal 24, e314-e318.

De Luca, C. J. (1997) The use of surface electromyography in biomechanics. J. Appl. Biomech. 13, 135-163.

Goiato, M. C., Zuim, P. R. J., Moreno, A., dos Santos, D. M., da Silva, E. V. F., de Caxias, F. P., Turcio, K. H. L. (2017) Does pain in the masseter and anterior temporal muscles influence maximal bite force? Arch. Oral Biol. 83, 1-6.

Gonçalves, L. M. N., Palinkas, M., Hallak, J. E. C., Marques Júnior, W., Vasconcelos, P. B., Frota, N. P. R., Regalo, I. H., Siéssere, S., Regalo, S. C. H. (2018) Alterations in the stomatognathic system due to amyotrophic lateral sclerosis. J. Appl. Oral Sci. 6, e20170408.

Haj-Mirzaian, A., Guermazi, A., Pishgar, F., Roemer, F. W., Sereni, C., Hakky, M., Zikria, B., Demehri, S. (2019) Patellofemoral morphology measurements and their associations with tibiofemoral osteoarthritisrelated structural damage: exploratory analysis on the osteoarthritis initiative. Eur. Radiol. 30, $128-140$.

Hermens, H. J., Freriks, B., Disselhorst-Klug, C., Rau, G. (2000) Development of recommendations for SEMG sensors and sensor placement procedures. J. Electromyogr. Kinesiol. 10, 361-374.

Kaimal, S., Ahmad, M., Kang, W., Nixdorf, D., Schiffman, E. L. (2018) Diagnostic accuracy of panoramic radiography and MRI for detecting signs of TMJ degenerative joint disease. Gen. Dent. 66, 34-40.

Komino, M., Shiga, H. (2017) Changes in mandibular movement during chewing of different hardness foods. Odontology 105, 418-425.

Kubota, M., Nakano, H., Sanjo, I., Satoh, K., Sanjo, T., Kamegai, T., Ishikawa, F. (1998) Maxillofacial morphology and masseter muscle thickness in adults. Eur. J. Orthod. 20, 535-542.

Kumai, T. (1993) Difference in chewing patterns between involved and opposite sides in patients with unilateral temporomandibular joint and myofascial pain-dysfunction. Arch. Oral Biol. 38, 467-478.

Lehman, R. A. Jr., Helgeson, M. D., Keeler, K. A., Bunmaprasert, T., Riew, K. D. (2009) Comparison of magnetic resonance imaging and computed tomography in predicting facet arthrosis in the cervical spine. Spine (Phila. Pa. 1976) 34, 65-68.

Lemos, G. A., da Silva, P. L. P., Batista, A. U. D., Palomari, E. T. (2018) Experimental model of temporomandibular joint arthritis: Evaluation of contralateral joint and masticatory muscles. Arch. Oral Biol. 95, 79-88.

Levorová, J., Machoň, V., Guha, A., Foltán, R. (2016) Osteoarthrosis of temporomandibular joint related to the defects of posterior dentition: a retrospective study. Prague Med. Rep. 117, 176-184.

Mau-Moeller, A., Jacksteit, R., Jackszis, M., Feldhege, F., Weippert, M., Mittelmeier, W. (2017) Neuromuscular function of the quadriceps muscle during isometric maximal, submaximal and submaximal fatiguing voluntary contractions in knee osteoarthrosis patients. PLoS One 12, e0176976. 
Mupparapu, M., Oak, S., Chang, Y. C., Alavi, A. (2019) Conventional and functional imaging in the evaluation of temporomandibular joint rheumatoid arthritis: a systematic review. Quintessence Int. 50, 742-753.

Palinkas, M., Nassar, M. S., Cecílio, F. A., Siéssere, S., Semprini, M., Machado-de-Sousa, J. P., Hallak, J. E., Regalo, S. C. (2010) Age and gender influence on maximal bite force and masticatory muscles thickness. Arch. Oral Biol. 55, 797-802.

Palinkas, M., Bataglion, C., De Luca Canto, G., Camolezi, N. M., Theodoro, G. T., Siéssere, S., Regalo, S. C. H. (2016) Impact of sleep bruxism on masseter and temporalis muscles and bite force. Cranio 34, 309-315.

Palinkas, M., Rodrigues, L., de Vasconcelos, P., Regalo, I., De Luca Canto, G., Siéssere, S., Regalo, S. (2018) Evaluation of the electromyographic activity of masseter and temporalis muscles of women with rheumatoid arthritis. Hippokratia 22, 3-9.

Rodrigues, L. A. M., Siéssere, S., De Luca Canto, G., Taube, O. L. S., Verri, E. D., Palinkas, L. G., Regalo, I. H., Regalo, S. C. H., Palinkas, M. (2017) Effect of rheumatoid arthritis on the masticatory muscles: Thickness, bite force, mandibular mobility and quality of life of adult women. Int. J. Oral Dent. Health 3, 1-6.

Santos, A. L., Demange, M. K., Prado, M. P., Fernandes, T. D., Giglio, P. N., Hintermann, B. (2014) Cartilage lesions and ankle osteoarthrosis: Review of the literature and treatment algorithm. Rev. Bras. Ortop. 49, 565-572.

Siéssere, S., Lima, N. A., Semprini, M., de Sousa, L. G., Issa, J. P. M., Monteiro, S. A. C., Regalo, S. C. H. (2009) Masticatory process in individuals with maxillary and mandibular osteoporosis: electromyographic analysis. Osteoporos. Int. 20, 1847-1851.

Smaglyuk, L. V., Liakhovska, A. V. (2019) EMG-characteristic of masticatory muscles in patients with class II malocclusion and temporomandibular disorders. Wiad. Lek. 72, 1043-1047.

Verri, E. D., da Silva, G. P., Fioco, E. F., da Silva, N. S., Fabrin, S. C. V., Zanella, C. A. B., Garrefa, C. R., Faria Júnior, M., Siéssere, S., Hallak, J. E. C., Palinkas, M., Chaves, T. C., Regalo, S. C. H. (2019) Effects of Parkinson's disease on molar bite force, electromyographic activity and muscle thickness of the masseter, temporal and sternocleidomastoid muscles: a case-control study. J. Oral Rehabil. 46, 912-919. 